\title{
Changing patient safety culture in China: a case study of an experimental Chinese hospital from a comparative perspective
}

This article was published in the following Dove Press journal: Risk Management and Healthcare Policy

\section{Xiao Ping $X u$, Dong Ning Deng,* Yong Hong Gu, Chui Shan Ng, Xiao Cai, Jun Xu, Xin Shi Zhang, Dong Ge Ke, Qian Hui Yu, Chi Kuen Chan \\ Clinical Service Department, The University of Hong Kong - Shenzhen Hospital, Shenzhen, Guangdong, People's Republic of China \\ *These authors contributed equally to this work}

Video abstract

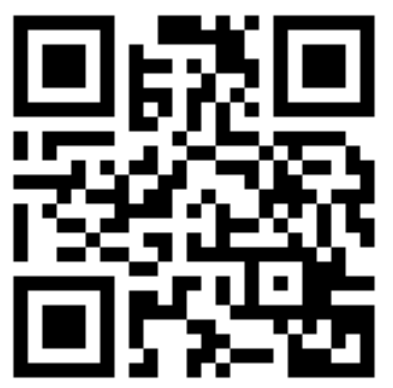

Point your SmartPhone at the code above. If you have a QR code reader the video abstract will appear. Or use: http://youtu.be/G618FIQJoPM

Correspondence: Xiao Ping Xu Clinical Service Department, The University of Hong Kong - Shenzhen Hospital, Research, Education and Administration Block, Room 1502, 5th Floor, No. I, Haiyuan Ist Road, Futian District, Shenzhen, Guangdong 518053 , People's Republic of China Email xuxp@hku-szh.org
Background: The World Health Organization highlights that patient safety interventions are not lacking but that the local context affects their successful implementation. Increasing attention is being paid to patient safety in Mainland China, yet few studies focus on patient safety in organizations with mixed cultures. This paper evaluates the current patient safety culture in an experimental Chinese hospital with a Hong Kong hospital management culture, and it aims to explore the application of Hong Kong's patient safety strategies in the context of Mainland China. Methods: A quantitative survey of 307 hospital staff members was conducted using the Hospital Survey on Patient Safety Culture questionnaire. The findings were compared with a similar study on general Chinese hospitals and were appraised with reference to the Manchester Patient Safety Framework.

Results: Lower scores were observed among participants with the following characteristics: males, doctors, those with more work experience, those with higher education, and those from the general practice and otolaryngology departments. However, the case study hospital achieved better scores in management expectations, actions and support for patient safety, incident reporting and communication, and teamwork within units. Its weaknesses were related to non-punitive responses to errors, teamwork across units, and staffing.

Conclusions: The case study hospital contributes to a changing patient safety culture in Mainland China, yet its patient safety culture remains mostly bureaucratic. Further efforts could be made to deepen the staff's patient safety culture mind-set, to realize a "bottom-up" approach to cultural change, to build up a comprehensive and integrated incident management system, and to improve team building and staffing for patient safety.

Keywords: patient safety, culture, Chinese hospital

\section{Background}

The concept of an organizational safety culture was first developed in the nuclear power industry after the Chernobyl accident in $1986 .{ }^{1}$ It refers to an organization's values, attitudes, feelings, capacities, and behavioral patterns to maintain a healthy and safe management atmosphere. ${ }^{2}$ In the healthcare field, the role of culture management is becoming increasingly important. ${ }^{3}$ In healthcare, a patient safety culture is crucial, as patient safety is a core element of healthcare quality and safety. ${ }^{4}$ Sammer et $\mathrm{al}^{5}$ summarized seven patient safety culture elements from the literature: leadership, teamwork, evidence-based care, communication, learning, just, and patient-centered care. Similarly, in an American patient safety survey questionnaire developed by the US Agency for Healthcare Research and Quality (AHRQ), namely, the Hospital Survey on Patient Safety Culture (HSOPSC), the dimensions of patient safety culture are teamwork, 
communication, incident reporting, non-punitive response to errors, management expectations, actions and support for patient safety, organizational learning, and staffing. ${ }^{6}$ Briefly, patient safety culture is a broad and complicated concept, and its management requires understandings of values, beliefs, norms, proper attitudes, and behaviors related to hospital development and patient safety. ${ }^{4,6}$

Sociologist Ron Westrum ${ }^{7}$ developed a typology of organizational safety culture that includes three levels: Pathological - power oriented, hiding information, covering up failures, and crushing new ideas; Bureaucratic - rule oriented, may ignore information, being just and merciful in the face of failure, and new ideas generating problems; Generative - performance oriented, actively seeking information, failure causes inquiry, and new ideas are embraced. It is believed that a real safety culture has been built up in an organization only when it reaches the generative level. ${ }^{8,9}$ To be practical, Reason ${ }^{10}$ extended Westrum's typology by adding two levels to the middle, Reactive and Proactive. Reason's five-level framework was also adopted in the Manchester Patient Safety Framework (MaPSaF) to evaluate the maturity of a hospital patient safety culture ${ }^{11}$ (Table 1). The MaPSaF was developed by the University of Manchester and the UK National Patient Safety Agency after reviewing the literature on patient safety in the UK National Health Service and collecting feedback from opinion leaders and interviewees. In the MaPSaF, aspects of patient safety culture are related to commitment to and prioritization of patient safety, incident investigation, perceptions and identification of their causes, organizational learning, communication, teamwork, personnel management, and relevant staff education and training. ${ }^{11}$

Table I Five-level framework of organizational safety culture

\begin{tabular}{|c|c|}
\hline Level & MaPSaF interpretation \\
\hline Pathological & $\begin{array}{l}\text { Organizations with a prevailing attitude of "why } \\
\text { waste our time on safety." Thus, there is little or no } \\
\text { investment in improving safety. }\end{array}$ \\
\hline Reactive & $\begin{array}{l}\text { Organizations that only think about safety after an } \\
\text { incident has occurred. }\end{array}$ \\
\hline Bureaucratic & $\begin{array}{l}\text { Organizations that are very paper based. Safety involves } \\
\text { ticking boxes to prove to auditors and assessors that } \\
\text { they are focused on safety. }\end{array}$ \\
\hline Proactive & $\begin{array}{l}\text { Organizations that place a high value on improving } \\
\text { safety, actively invest in continuous safety } \\
\text { improvements, and reward staff who raise safety- } \\
\text { related issues. }\end{array}$ \\
\hline Generative & $\begin{array}{l}\text { Organizations in which safety is an integral part of } \\
\text { everything that they do. In a generative organization, } \\
\text { safety is truly in the hearts and minds of everyone, from } \\
\text { senior managers to frontline staff. }\end{array}$ \\
\hline
\end{tabular}

Abbreviation: MaPSaF, Manchester Patient Safety Framework.
Each aspect is described in detail at each of the five levels of organizational safety culture. Researchers can use these descriptions to critically appraise their findings and to evaluate how well their organizations are doing in each aspect of patient safety.

The development of a patient safety culture in China has lagged behind that of more developed countries. For example, the first patient safety movement occurred in the USA in $2000,{ }^{12}$ while there seems to be little formal social attention paid to this aspect in Mainland China. In Mainland China, a focus on patient safety occurred no earlier than 2007. ${ }^{13}$ Moreover, while there have been many influential studies on patient safety in developed countries, such as those mentioned above, a review of Chinese patient safety studies ${ }^{14}$ concluded that the overall quality of those studies needs improvement, especially in terms of methodological rigor.

In 2010, as part of the Chinese healthcare system reform, new actors were encouraged by the Chinese government to establish healthcare institutions. ${ }^{15}$ Specifically, stakeholders from Hong Kong, Macau, and Taiwan will enjoy more policy support in this area. ${ }^{15}$ Under this policy, in 2012, the Shenzhen city government cooperated with the University of Hong Kong to establish the University of Hong Kong Shenzhen Hospital (HKUSZH). This hospital is part of a trend in Mainland China of introducing overseas hospital management strategies to accelerate the reform of Chinese public hospitals. HKUSZH has adopted a Hong Kong hospital management culture and strategy, one aspect of which is patient safety management. Compared with the Mainland, Hong Kong is more experienced in patient safety, as its focus on patient safety precedes that of the Mainland. In the late 20th century, the Hong Kong Hospital Authority began to pay considerable attention to service quality and patient safety in order to realize its Corporate Vision 2000. ${ }^{16}$ Thus, many comparatively new patient safety strategies have been implemented in HKUSZH, such as establishing a special team in charge of incident management, using scientific methods such as root cause analysis (RCA) to conduct formal and completely exclusive investigations into severe incidents.

The World Health Organization (WHO) ${ }^{17}$ indicates that there is no lack of interventions to improve patient safety, but local contexts and cultures affect their successful application. As the first experimental public hospital in the public hospital reform, it is still unclear how the Hong Kong patient safety culture and strategies will function in the Mainland context. It will be interesting and meaningful to explore the application of Hong Kong's patient safety strategies in Mainland China. 
Important lessons can be learned and applied to similar cases in Mainland China.

\section{Methods}

This paper aims to evaluate the current patient safety culture in HKUSZH and to analyze the differences and similarities compared to Chinese hospitals in general. First, quantitative patient safety culture data were obtained using the HSOPSC questionnaire. The second step of this study was to summarize the results of the questionnaire into three parts: factors that influence patient safety culture, incident reporting rates and overall grading, and dimensional results. These findings for HKUSZH were then critically appraised using the MaPSaF. Further research and suggestions for improvement were then discussed based on the MaPSaF. Moreover, the results were compared with the findings of similar studies, one with 1160 Chinese participants in 15 hospitals in Mainland China ${ }^{18}$ and another with 447,584 US participants in 680 hospitals in the USA. ${ }^{6}$

\section{HSOPSC questionnaire}

The HSOPSC questionnaire has been used in different cultures and has been proven to be a valid tool for culture evaluation. In Mao et al's review ${ }^{19}$ of patient safety culture research, the HSOPSC was the most popular patient safety questionnaire. It has also been used in many Chinese studies. ${ }^{13,18,20}$ HSOPSC has three main parts: population information, a 42-item and 12-dimension measurement scale, and two extra questions about the overall patient safety grade for their unit and the number of events they reported over the past 12 months. ${ }^{21}$ The items are measured on a 5-point Likert scale of agreement (from 1 [strongly disagree] to 5 [strongly agree]) or frequency (from 1 [never] to 5 [always]). The question about the overall grade is rated on a 5-point scale of performance (from 1 [failing] to 5 [excellent]). The question about reporting frequency is rated on a 6-point scale based on the number of reported incidents $(0,1-2,3-5,6-10,11-20, \geq 21)$.

A translator with an overseas degree in healthcare social policy translated the HSOPSC into Chinese, the HKUSZHHSOPSC, for this study. Another translator from Hong Kong with working experience in hospital management doublechecked and revised the instrument. A pilot survey was conducted with 45 HKUSZH staff (clinical and nonclinical) to test whether the Chinese expressions were appropriate. Only a few modifications were made after that.

\section{Sampling and survey}

The sample was drawn from the staff of HKUSZH. The survey covered clinical, support, and administrative departments. Convenience sampling was used, and the sample from each department was calculated according to the ratio of staff members in each department to the total number of hospital staff members.

Investigators were trained before fielding the survey. The questionnaire was administered on paper and completed anonymously. The formal survey was conducted with 309 staff members on May 2016. The response rate was $99.35 \%$.

\section{Ethics approval and consent to participate}

This study has received ethics approval from HKUSZH Medical Ethics Committee. Written informed consent was obtained from participants before completion of the survey.

\section{Statistical analysis}

According to the AHRQ, ${ }^{6}$ all results (overall grade, reporting frequency, dimensions, and items results) are presented as the percentage of positive response. For example, the question on the overall grade was reported as the percentage sum of 4 (very good) and 5 (excellent) responses. The question on reporting frequency was reported as the percentage sum of all other options except " 0 ". In terms of the positively worded items, the positive response is the percentage sum of $4 \mathrm{~s}$ (agree) and $5 \mathrm{~s}$ (strongly agree) on the 5-point scale. The dimensional results were reported as the mean values of the related items. For convenience, the results of negatively worded items were recoded before analysis. Thus, all item results were calculated in the same way as the positively worded items.

Because the data were not normally distributed after Kolmogorov-Smirnov tests, we use nonparametric KruskalWallis $(\mathrm{K}-\mathrm{W})$ tests to compare attitude toward patient safety culture among different characteristic groups. Four characteristics - gender, work experience, educational level, and profession - were evaluated via $\mathrm{K}-\mathrm{W}$ tests to determine whether differences in dimensional and item scores were significant. If $P$-value is $>0.05$, the difference in the characteristic is not significant.

\section{Results Comparing group results}

The demographic characteristics of the participants are shown in Table 2. Most of them are female, nurses, with bachelor's degrees, and 6-10 years of working experience in their specialty. The $\mathrm{K}-\mathrm{W}$ test results are presented in Table 3 . Among the characteristics with significant differences on 
some dimensional scores, those associated with more positive patient safety culture scores are being female, having less work experience ( $\leq 5$ years), having a lower educational level (sbachelor's degree), being a nurse (except D7 and D10), and working in the ophthalmology department (except D5). In contrast, those associated with more negative scores

Table 2 Demographic characteristics of formal survey participants

\begin{tabular}{lll}
\hline Sample details & & Valid response $^{\mathrm{a}} \mathbf{( \% )}$ \\
\hline Gender & Female & 80.8 \\
& Male & 19.2 \\
Education level & Bachelor's degree & 61.9 \\
& Master's degree or higher & 23.5 \\
& Below bachelor's degree & 14.6 \\
Time working & 6-10 years & 37.8 \\
in specialty & I-5 years & 29.4 \\
& II-15 years & 16.1 \\
& LI year & 6.0 \\
& I6-20 years & 5.4 \\
Profession & $\geq 21$ years & 5.4 \\
& Nurse & 45.8 \\
& Doctor & 24.6 \\
& Technician/others & 16.3 \\
& Administrative staff & 13.3 \\
\hline
\end{tabular}

Note: ${ }^{\mathrm{V}}$ alid response is the response rate after missing data were removed. are being male, having more work experience (10-20 years), having a higher educational level ( $\geq$ master's degree), being a doctor (except D6), and working in the general practice and otolaryngology departments (except D9).

\section{Comparing within the most influential groups}

Table 3 shows that the profession group is associated with significant differences on six dimensions (D5, D6, D7, D8, D10, and D12), while other characteristics are associated with significant differences on less than six dimensions. Thus, we consider the profession the most influential characteristic in the HKUSZH data set. Specifically, two subgroups within the profession group, nurse and doctor, were the most divergent on attitudes toward patient safety culture. Therefore, exploring the patient safety culture attitudes within the nurse group and the doctor group is a special focus of our comparative study.

The quality of medical practice is closely related to the healthcare worker's education level and work experience. Table 4 shows the attitudes of doctors and nurses with different levels of education and work experience toward patient safety culture. $\mathrm{K}-\mathrm{W}$ test results show that only a few

Table 3 Results of Kruskal -Wallis test for independent samples

\begin{tabular}{|c|c|c|c|c|}
\hline \multirow[t]{2}{*}{ Dimensions } & \multicolumn{4}{|l|}{ P-value } \\
\hline & Gender & Working years & Education level & Profession \\
\hline DI. Teamwork within Unit & 0.951 & 0.803 & 0.064 & 0.412 \\
\hline D2. Supervisor/Manager Expectation and & 0.689 & 0.547 & 0.157 & 0.21 \\
\hline \multicolumn{5}{|l|}{ Actions Promoting Patient Safety } \\
\hline D3. Organizational Learning -Continuous & 0.389 & 0.645 & 0.51 & 0.191 \\
\hline \multicolumn{5}{|l|}{ Improvement } \\
\hline D4. Management Support for Patient Safety & 0.963 & 0.934 & 0.132 & 0.777 \\
\hline D5. Feedback and Communication about & 0.134 & 0.82 & 0.089 & 0 \\
\hline Errors & & & & (Nurse, Doctor) \\
\hline \multirow[t]{2}{*}{ D6. Frequency of Events Reported } & 0.269 & 0.187 & 0.059 & 0.005 \\
\hline & & & & (Nurse, Other) \\
\hline \multirow[t]{2}{*}{ D7. Overall Perception of Patient Safety } & 0.591 & 0.066 & 0.49 & 0.023 \\
\hline & & & & (Other, Doctor) \\
\hline \multirow[t]{2}{*}{ D8. Communication Openness } & 0.035 & 0.173 & 0.002 & 0 \\
\hline & (Female, Male) & & ( $\leq$ Bachelor's, $\geq$ Master's) & (Nurse, Doctor) \\
\hline \multirow[t]{3}{*}{ D9. Teamwork across Units } & 0.859 & 0.03 & 0.748 & 0.302 \\
\hline & & $(\leq 5$ years, $10-20$ & & \\
\hline & & years) & & \\
\hline \multirow[t]{2}{*}{ DI0. Staffing } & 0.03 & 0.259 & 0.015 & 0 \\
\hline & (Female, Male) & & ( $\leq$ Bachelor's, $\geq$ Master's) & (Other, Doctor) \\
\hline \multirow[t]{2}{*}{ DII. Handoffs and Transitions } & 0.747 & 0.158 & 0.016 & 0.397 \\
\hline & & & ( $\leq$ Bachelor's, $\geq$ Master's) & \\
\hline \multirow[t]{2}{*}{ DI2. Non-punitive Response to Errors } & 0.041 & 0.597 & 0.022 & 0.001 \\
\hline & (Female, Male) & & ( $\leq$ Bachelor's, $\geq$ Master's) & (Nurse, Doctor) \\
\hline
\end{tabular}

Notes: The significance level is 0.05 . Bold figures indicate $P<0.05$, the dimension score shows significant difference for that characteristic. $P$-values in bold shows characteristics of those with the Most Positive responses are presented on the left, characteristics of those with the Most Negative responses are presented on the right. Abbreviation: D, dimension. 
dimensions and items had significant differences. Specifically, doctors with more education had more positive views of procedures and systems in place to prevent errors (a18). Doctors' work experience showed an unclear pattern with regard to their attitudes toward patient safety. While doctors with 10-20 years of experience are less positive than those with $<5$ years experience (b1, a9, f1, d3, c4, and D7), most of those with over 20 years experience are as positive as younger doctors ( $\mathrm{a} 9, \mathrm{f1}, \mathrm{c} 4$, and D7). This unclear pattern also exists in nurses' attitudes toward staffing for patient safety by the amount of work experience (a7 and D10). There is no significant difference in the attitudes of nurses toward patient safety culture by their level of education (Table 4).

\section{Comparing patient safety culture results: strengths and areas for improvement}

Table 5 shows the positive response rate for the overall grade, reporting frequency, dimensions, and items. The results for HKUSZH were compared with survey results from Mainland China $^{18}$ and the USA. ${ }^{6}$ Figure 1 shows the distribution of dimensional positive response rates from all three surveys compared to the average positive response rate for HKUSZH along all dimensions (Line A in Figure 1). The strong areas of HKUSZH are an open and fair organizational culture for patient safety and an overall commitment to and prioritization of patient safety. Areas for improvements are a non-punitive culture, teamwork for patient safety, and hospital personnel management.

\section{An open and fair organizational culture for patient safety}

The relevant results regarding the openness and fairness of patient safety culture in HKUSZH are similar to those for the USA and are much more advanced than those for Mainland China in general. Specifically, HKUSZH's positive response in overall grading $(84.9 \%)$ was higher than that in both the Mainland China survey (73\%) and the US survey (76\%). HKUSZH's positive response in reporting frequency (45.7\%) was also slightly higher than that in the US survey (45\%). Meanwhile, in the dimension and items related to feedback and communication about errors (D5), respondents from HKUSZH were much more positive (71.8\%) than those from Mainland China (50.0\%) and the USA (68.0\%).

\section{Overall commitment to and prioritization of patient safety}

HKUSZH is also strong in its management team's commitment to and prioritization of patient safety. HKUSZH's positive responses in two dimensions, management expectations and actions (D2: 80.8\%) and management support (D4: 75.5\%), are both higher than the corresponding values for the USA (D2: 78.0\%, D4: 72.0\%) and Mainland China (D2: 63.0\%, D4: 69.0\%). HKUSZH's results for the items under these two dimensions are mostly better than those in the other two surveys, except two items: b3 in D2, where HKUSZH (58.0\%) is lower than the USA (77.0\%) but higher than Mainland China (36.0\%), and 99 in D4, where HKUSZH $(59.9 \%)$ is the lowest (Mainland: $65.0 \%$, USA: $61.0 \%$ ).

\section{Non-punitive culture}

Some results also reveal potential areas for improvement. In terms of a non-punitive culture (D12), HKUSZH obtained a low positive response (31.8\%); indeed this is lower than in the USA (45.0\%) and, interestingly, much lower than in Mainland China (60.0\%). The item results show that HKUSZH respondents are much more likely to worry that mistakes will be held against them (a8) and will be kept in a personnel file (a16).

\section{Teamwork for patient safety}

The HKUSZH results for teamwork within units (D1) and across units (D9) diverge. Teamwork within units is one of HKUSZH's strength (HKUSZH: $87.4 \%$, Mainland: $84.0 \%$, USA: $82.0 \%$ ). HKUSZH has the most positive response for all other items under D1, except item a3 (HKUSZH: 85.3\%, Mainland: $87 \%$, USA: $87 \%$ ). On the contrary, HKUSZH is weak at teamwork across units (HKUSZH: $50.0 \%$, Mainland: $66.0 \%$, USA: $61.0 \%$ ). Similarly, HKUSZH is weak in all D9 items.

\section{Hospital personnel management}

Staffing (D10) is another area for improvement (HKUSZH: $32.9 \%$, Mainland: $45.0 \%$, USA: $54.0 \%$ ), especially in terms of working hours (a5), as HKUSZH has only $12.6 \%$ positive response (Mainland: $38.0 \%$, USA: $50.0 \%$ ).

\section{Discussion}

\section{Factors that influence patient safety culture}

Some observations that emerge from HKUSZH's profession groups (Table 3) are consistent with the findings of other HSOPSC studies on Chinese samples. ${ }^{18,22}$ For example, Nie et $\mathrm{al}^{18}$ and $\mathrm{Zhu}$ et $\mathrm{a}^{22}$ examined large samples in Chinese hospitals and found that doctors are more likely to have negative attitudes toward patient safety culture, while nurses are the opposite. This finding in HKUSZH case study provides 
Table 4 Patient safety culture attitudes of doctors and nurses with different educational levels and working years

\begin{tabular}{|c|c|c|c|c|c|}
\hline \multirow[t]{3}{*}{ Items/Dimension } & \multicolumn{5}{|c|}{ Positive responses of doctors (\%) } \\
\hline & \multicolumn{2}{|c|}{ Educational level } & \multirow[t]{2}{*}{ P-value } & \multicolumn{2}{|c|}{ Working years } \\
\hline & $\begin{array}{l}\leq \text { Bachelor's } \\
\text { degree }\end{array}$ & $\begin{array}{l}\geq \text { Master's } \\
\text { degree }\end{array}$ & & $<5$ & $5-10$ \\
\hline DI. Teamwork within Units & 1 & 1 & 0.758 & 1 & 1 \\
\hline al. People support one another in this facility & 1 & 1 & 0.532 & 1 & 1 \\
\hline $\begin{array}{l}\text { a3. When a lot of work needs to be done quickly, we work together as a team } \\
\text { to get the work done }\end{array}$ & 1 & 1 & 0.663 & 1 & 1 \\
\hline a4. In this facility, people treat each other with respect & 1 & 1 & 0.362 & 1 & 1 \\
\hline al I. When one area in this unit gets really busy, others help out & 1 & 1 & 0.356 & 1 & 1 \\
\hline $\begin{array}{l}\text { D2. Supervisor/Manager Expectations and Actions Promoting } \\
\text { Patient Safety }\end{array}$ & 1 & 1 & 0.161 & 1 & 1 \\
\hline $\begin{array}{l}\text { bI. My supervisor/manager says a good word when he/she sees a job done } \\
\text { according to established patient safety procedures }\end{array}$ & 1 & 1 & 0.086 & 90.5 & 90.9 \\
\hline $\begin{array}{l}\text { b2. My supervisor/manager seriously considers staff suggestions for improving } \\
\text { patient safety }\end{array}$ & 1 & 1 & 0.12 & 1 & 1 \\
\hline $\begin{array}{l}\text { b3r. Whenever pressure builds up, my supervisor/manager wants us to work } \\
\text { faster, even if it means taking shortcuts }\end{array}$ & 1 & 1 & 0.344 & 1 & 1 \\
\hline $\begin{array}{l}\text { b4r. My supervisor/manager overlooks patient safety problems that happen } \\
\text { over and over }\end{array}$ & 1 & 1 & 0.629 & 1 & 1 \\
\hline D3. Organizational Learning - Continuous Improvement & 1 & 1 & 0.123 & 1 & 1 \\
\hline a6. We are actively doing things to improve patient safety & 1 & 1 & 0.397 & 1 & 1 \\
\hline a9. Mistakes have led to positive changes here & 1 & 1 & 0.095 & 52.4 & 63.6 \\
\hline $\begin{array}{l}\text { al3. After we make changes to improve patient safety, we evaluate their } \\
\text { effectiveness }\end{array}$ & 1 & 1 & 0.133 & 1 & 1 \\
\hline D4. Management Support for Patient Safety & 1 & 1 & 0.251 & 1 & 1 \\
\hline fl. Hospital management provides a work climate that promotes patient safety & 1 & 1 & 0.866 & 76.2 & 82.6 \\
\hline $\begin{array}{l}\text { f8. The actions of hospital management show that patient safety is a top } \\
\text { priority }\end{array}$ & 1 & 1 & 0.249 & 1 & 1 \\
\hline $\begin{array}{l}\text { f9r. Hospital management seems interested in patient safety only after an } \\
\text { adverse event }\end{array}$ & 1 & 1 & 0.729 & 1 & 1 \\
\hline D5. Feedback and Communication about Errors & 1 & 1 & 0.095 & 1 & 1 \\
\hline $\begin{array}{l}\mathrm{cl} \text {. We are given feedback about changes put into place based on event } \\
\text { reports }\end{array}$ & 1 & 1 & 0.627 & 1 & 1 \\
\hline c3. We are informed about errors that happen here & 1 & 1 & 0.061 & 1 & 1 \\
\hline c5. In this unit, we discuss ways to prevent errors from happening again & 1 & 1 & 0.158 & 1 & 1 \\
\hline D6. Frequency of Events Reported & 1 & 1 & 0.442 & 1 & 1 \\
\hline $\begin{array}{l}\text { dl. When a mistake is made but is caught and corrected before affecting the } \\
\text { patient, how often is this reported? }\end{array}$ & 1 & 1 & 0.565 & 1 & 1 \\
\hline $\begin{array}{l}\text { d2. When a mistake is made but has no potential to harm the patient, how } \\
\text { often is this reported? }\end{array}$ & 1 & 1 & 0.449 & 1 & 1 \\
\hline $\begin{array}{l}\text { d3. When a mistake is made that could harm the patient but does not, how } \\
\text { often is this reported? }\end{array}$ & 1 & 1 & 0.59 & 65.0 & 82.6 \\
\hline D7. Overall Perceptions of Patient Safety & 1 & 1 & 0.103 & 76.19 & 56.52 \\
\hline $\begin{array}{l}\text { a IOr. It is just by chance that more serious mistakes do not happen around } \\
\text { here }\end{array}$ & 1 & 1 & 0.12 & 1 & 1 \\
\hline a 15. Patient safety is never sacrificed to get more work done & 1 & 1 & 0.663 & 1 & 1 \\
\hline a 17r. We have patient safety problems in this unit & 1 & 1 & 0.571 & 1 & 1 \\
\hline a 18. Our procedures and systems are good at preventing errors & 52.6 & 77.8 & 0.031 & 1 & 1 \\
\hline D8. Communication Openness & 1 & 1 & 0.549 & 1 & 1 \\
\hline $\begin{array}{l}\text { c2. Staff will freely speak up if they see something that may negatively affect } \\
\text { patient care }\end{array}$ & 1 & 1 & 0.545 & 1 & 1 \\
\hline $\begin{array}{l}\text { c4. Staff feel free to question the decisions or actions of those with more } \\
\text { authority }\end{array}$ & 1 & 1 & 0.402 & 55.0 & 50.0 \\
\hline c6r. Staff are afraid to ask questions when something does not seem right & 1 & 1 & 0.425 & 1 & 1 \\
\hline
\end{tabular}




\begin{tabular}{|c|c|c|c|c|c|c|c|c|c|c|}
\hline \multirow[b]{3}{*}{$10-20$} & \multirow[b]{3}{*}{$>20$} & \multirow{3}{*}{$P$-value } & \multicolumn{8}{|c|}{ Positive responses of nurses (\%) } \\
\hline & & & \multicolumn{2}{|c|}{ Educational level } & \multirow[t]{2}{*}{$P$-value } & \multicolumn{4}{|c|}{ Working years } & \multirow[t]{2}{*}{$P$-value } \\
\hline & & & $\begin{array}{l}\text { SBachelor's } \\
\text { degree }\end{array}$ & $\begin{array}{l}\geq \text { Master's } \\
\text { degree }\end{array}$ & & $<5$ & $5-10$ & $10-20$ & $>20$ & \\
\hline 1 & 1 & 0.327 & 1 & 1 & 0.447 & 1 & 1 & 1 & 1 & 0.892 \\
\hline 1 & 1 & 0.072 & 1 & 1 & $0.77 \mid$ & 1 & 1 & 1 & 1 & 0.621 \\
\hline 1 & 1 & 0.099 & 1 & 1 & 0.058 & 1 & 1 & 1 & 1 & 0.565 \\
\hline 1 & 1 & 0.189 & 1 & 1 & 0.459 & 1 & 1 & 1 & 1 & 0.83 \\
\hline 1 & 1 & 0.649 & 1 & 1 & 0.96 & 1 & 1 & 1 & 1 & 0.548 \\
\hline 1 & 1 & 0.502 & 1 & 1 & 0.77 & 1 & 1 & 1 & 1 & 0.766 \\
\hline 84.0 & 80.0 & 0.033 & 1 & 1 & 0.486 & 1 & 1 & 1 & 1 & 0.889 \\
\hline 1 & 1 & 0.286 & 1 & 1 & 0.62 & 1 & 1 & 1 & 1 & 0.666 \\
\hline 1 & 1 & 0.158 & 1 & 1 & 0.472 & 94.1 & 84.3 & 81.8 & 100.0 & 0.038 \\
\hline 1 & 1 & 0.265 & 1 & 1 & 0.343 & 1 & 1 & 1 & 1 & 0.662 \\
\hline 1 & 1 & 0.139 & 1 & 1 & 0.972 & 1 & 1 & 1 & 1 & 0.223 \\
\hline 1 & 1 & 0.17 & 1 & 1 & 0.746 & 1 & 1 & 1 & 1 & 0.116 \\
\hline 33.3 & 80.0 & 0.029 & 1 & 1 & 0.961 & 1 & 1 & 1 & 1 & 0.166 \\
\hline 1 & 1 & 0.209 & 1 & 1 & 0.698 & 1 & 1 & 1 & 1 & 0.056 \\
\hline 1 & 1 & 0.191 & 1 & 1 & 0.33 & 1 & 1 & 1 & 1 & 0.898 \\
\hline 70.8 & 100.0 & 0.01 & 1 & 1 & 0.206 & 1 & 1 & 1 & 1 & 0.688 \\
\hline 1 & 1 & 0.328 & 1 & 1 & 0.9 & 1 & 1 & 1 & 1 & 0.951 \\
\hline 1 & 1 & 0.813 & 1 & 1 & 0.914 & 1 & 1 & 1 & 1 & 0.711 \\
\hline 1 & 1 & 0.447 & 1 & 1 & 0.911 & 1 & 1 & 1 & 1 & 0.818 \\
\hline 1 & 1 & 0.694 & 1 & 1 & 0.812 & 1 & 1 & 1 & 1 & 0.388 \\
\hline 1 & 1 & 0.099 & 1 & 1 & 0.816 & 1 & 1 & 1 & 1 & 0.496 \\
\hline 1 & 1 & 0.358 & 1 & 1 & 0.842 & 1 & 1 & 1 & 1 & 0.969 \\
\hline 1 & 1 & 0.505 & 1 & 1 & 0.835 & 1 & 1 & 1 & 1 & 0.334 \\
\hline 1 & 1 & 0.902 & 1 & 1 & 0.679 & 1 & 1 & 1 & 1 & 0.172 \\
\hline 1 & 1 & 0.101 & 1 & 1 & 0.777 & 1 & 1 & 1 & 1 & 0.433 \\
\hline 54.2 & 40.0 & 0.038 & 1 & 1 & 0.812 & 1 & 1 & 1 & 1 & 0.616 \\
\hline 56 & 80 & 0.047 & 1 & 1 & 0.355 & 1 & 1 & 1 & 1 & 0.791 \\
\hline 1 & 1 & 0.539 & 1 & 1 & $0.64 I$ & 1 & 1 & 1 & 1 & 0.191 \\
\hline 1 & 1 & 0.145 & 1 & 1 & 0.212 & 1 & 1 & 1 & 1 & 0.342 \\
\hline 1 & 1 & 0.056 & 1 & 1 & 0.758 & 1 & 1 & 1 & 1 & 0.363 \\
\hline 1 & 1 & 0.194 & 1 & 1 & 0.149 & 1 & 1 & 1 & 1 & 0.242 \\
\hline 1 & 1 & 0.155 & 1 & 1 & 0.632 & 1 & 1 & 1 & 1 & 0.878 \\
\hline 1 & 1 & 0.346 & 1 & 1 & 0.896 & 1 & 1 & 1 & 1 & $0.87 \mid$ \\
\hline 29.2 & 40.0 & 0.02 & 1 & 1 & 0.766 & 1 & 1 & 1 & 1 & 0.994 \\
\hline 1 & 1 & 0.101 & 1 & 1 & 0.536 & 1 & 1 & 1 & 1 & 0.243 \\
\hline
\end{tabular}


Table 4 (Continued)

\begin{tabular}{|c|c|c|c|c|c|}
\hline \multirow[t]{3}{*}{ Items/Dimension } & \multicolumn{5}{|c|}{ Positive responses of doctors (\%) } \\
\hline & \multicolumn{2}{|c|}{ Educational level } & \multirow[t]{2}{*}{ P-value } & \multicolumn{2}{|c|}{ Working years } \\
\hline & $\begin{array}{l}\leq \text { Bachelor's } \\
\text { degree }\end{array}$ & $\begin{array}{l}\geq \text { Master's } \\
\text { degree }\end{array}$ & & $<5$ & $5-10$ \\
\hline D9. Teamwork across Units & 1 & 1 & 0.186 & 1 & 1 \\
\hline f2r. Hospital units do not coordinate well with each other & 1 & 1 & 0.234 & 1 & 1 \\
\hline f4. There is good cooperation among hospital units that need to work together & 1 & 1 & 0.983 & 1 & 1 \\
\hline f6r. It is often unpleasant to work with staff from other hospital units & 1 & 1 & 0.065 & 1 & 1 \\
\hline fl0. Hospital units work well together to provide the best care for patients & 1 & 1 & 0.864 & 1 & 1 \\
\hline DI0.Staffing & 1 & 1 & 0.644 & 1 & 1 \\
\hline a2. We have enough staff to handle the workload & 1 & 1 & 0.885 & 1 & 1 \\
\hline a5r. Staff members in this unit work longer hours than is best for patient care & 1 & 1 & 0.761 & 1 & 1 \\
\hline a7r. We use more agency/temporary staff than is best for patient care & 1 & 1 & 0.713 & 1 & 1 \\
\hline a $14 r$. We work longer hours than is best for patient care in this unit & 1 & 1 & 0.844 & 1 & 1 \\
\hline DI I. Handoffs and Transitions & 1 & 1 & 0.102 & 1 & 1 \\
\hline $\begin{array}{l}\text { f3r. Things "fall through the cracks" when transferring patients from one unit } \\
\text { to another }\end{array}$ & 1 & 1 & 0.176 & 1 & 1 \\
\hline f5r. Important patient care information is often lost during shift changes & 1 & 1 & 0.502 & 1 & 1 \\
\hline f7r. Problems often occur in the exchange of information across hospital units & 1 & 1 & 0.13 & 1 & 1 \\
\hline fIIr. Shift changes are problematic for patients in this hospital & 1 & 1 & 0.462 & 1 & 1 \\
\hline D I 2. Non-punitive Response to Errors & 1 & 1 & 0.476 & 1 & 1 \\
\hline a8r. Staff members feel like their mistakes are held against them & 1 & 1 & 0.446 & 1 & 1 \\
\hline $\begin{array}{l}\text { a } 2 r \text {. When an event is reported, it feels like the person is being written up, } \\
\text { not the problem }\end{array}$ & 1 & 1 & 0.979 & 1 & 1 \\
\hline a 16r. Staff worry that mistakes are kept in their personnel files & 1 & 1 & 0.74 & 1 & 1 \\
\hline
\end{tabular}

Notes: The significance level is 0.05 , where $P>0.05$ means the dimension score shows no significant difference for that characteristic. The table shows only positive responses where there is significant difference for that characteristic. The " $r$ " after the item number indicates negatively worded items; the results of negatively worded items were recoded before analysis. Thus, all item results were calculated in the same way as the positively worded items. "I" means the dimension or item score shows no significant difference under such character $(P>0.05)$. A bold figure is the dimension or item score which show significant difference under such character $(P<0.05)$.

Abbreviation: $\mathrm{D}$, dimension.

additional evidence for Nie et al's explanation that Chinese professional training for nurses contributes to a more positive attitude toward patient safety issues among Chinese nurse. ${ }^{18}$

Nevertheless, this paper raises some questions and invites further exploration, such as whether Chinese doctors have the most responsibility for and pressure regarding patient safety, which would explain why they tend to be more negative here. As every healthcare worker has an equal responsibility for patient safety, it might be unfair that one group has more responsibility or feels more pressure regarding patient safety than another. Management attention might be needed here. More relevant training can be given to doctors to enhance their capacity to build a patient safety culture. Other explorations could include the meaning of an ideal safety culture among different groups and what it means for these groups to accept the new HKUSZH culture.

The results for the attitudes of doctors and nurses with different educational and work experience levels are not clear enough to compare to other studies. This might be due to the small sample size in this study. In Nie et al ${ }^{18}$ and $\mathrm{Zhu}$ et al, ${ }^{22}$ for example, there were over 1000 respondents from several hospitals, while this study has only 307 participants and is a case study of only one hospital. Qualitative studies are recommended to produce more meaningful findings. For instance, why doctors who have medium levels of work experience (5-20 years) have more negative attitudes toward the patient safety culture than those with the least ( $<5$ years) and the most experience ( $>20$ years)?

\section{Overall commitment to and prioritization of patient safety: a top-down culture change approach might be bureaucratic if it does not reach all}

Divergences between HKUSZH and Mainland China are seen in dimensions related to management's commitment and priority to patient safety (D2 and D4). HKUSZH's results are remarkably higher, especially in D2. It seems that HKUSZH's top management team is more committed to patient safety than those of other general hospitals in Mainland China. They think highly of staff ideas to improve patient safety, and they make patient safety a top priority in hospital service. For example, the hospital's Incident Management Team (IMT) was established to address 


\begin{tabular}{|c|c|c|c|c|c|c|c|c|c|c|}
\hline \multirow[b]{3}{*}{$10-20$} & \multirow[b]{3}{*}{$>20$} & \multirow{3}{*}{$P$-value } & \multicolumn{8}{|c|}{ Positive responses of nurses (\%) } \\
\hline & & & \multicolumn{2}{|c|}{ Educational level } & \multirow[t]{2}{*}{$P$-value } & \multicolumn{4}{|c|}{ Working years } & \multirow[t]{2}{*}{ P-value } \\
\hline & & & $\begin{array}{l}\text { SBachelor's } \\
\text { degree }\end{array}$ & $\begin{array}{l}\geq \text { Master's } \\
\text { degree }\end{array}$ & & $<5$ & $5-10$ & $10-20$ & $>20$ & \\
\hline 1 & 1 & 0.057 & 1 & 1 & 0.74 & 1 & 1 & 1 & 1 & 0.166 \\
\hline 1 & 1 & 0.11 & 1 & 1 & 0.391 & 1 & 1 & 1 & 1 & 0.319 \\
\hline 1 & 1 & 0.34 & 1 & 1 & 0.458 & 1 & 1 & 1 & 1 & 0.811 \\
\hline 1 & 1 & 0.46 & 1 & 1 & 0.26 & 1 & 1 & 1 & 1 & 0.299 \\
\hline 1 & 1 & 0.146 & 1 & 1 & 0.96 & 1 & 1 & 1 & 1 & 0.592 \\
\hline 1 & 1 & 0.78 & 1 & 1 & 0.102 & 8.3 & 4.5 & 16.7 & 0 & 0.048 \\
\hline 1 & 1 & 0.853 & 1 & 1 & 0.669 & 1 & 1 & 1 & 1 & 0.522 \\
\hline 1 & 1 & 0.409 & 1 & 1 & 0.292 & 1 & 1 & 1 & 1 & 0.119 \\
\hline 1 & 1 & 0.501 & 1 & 1 & 0.819 & 72.7 & 89.1 & 70.0 & 80.0 & 0.028 \\
\hline 1 & 1 & 0.167 & 1 & 1 & 0.071 & 1 & 1 & 1 & 1 & 0.472 \\
\hline 1 & 1 & 0.667 & 1 & 1 & 0.776 & 1 & 1 & 1 & 1 & 0.479 \\
\hline 1 & 1 & 0.544 & 1 & 1 & 0.365 & 1 & 1 & 1 & 1 & 0.987 \\
\hline 1 & 1 & 0.076 & 1 & 1 & 0.634 & 1 & 1 & 1 & 1 & 0.337 \\
\hline 1 & 1 & 0.076 & 1 & 1 & 0.231 & 1 & 1 & 1 & 1 & 0.186 \\
\hline 1 & 1 & 0.156 & 1 & 1 & 0.749 & 1 & 1 & 1 & 1 & 0.668 \\
\hline 1 & 1 & 0.909 & 1 & 1 & 0.396 & 1 & 1 & 1 & 1 & 0.728 \\
\hline 1 & 1 & 0.079 & 1 & 1 & 0.169 & 1 & 1 & 1 & 1 & 0.073 \\
\hline 1 & 1 & 0.459 & 1 & 1 & 0.657 & 1 & 1 & 1 & 1 & 0.931 \\
\hline 1 & 1 & 0.439 & 1 & 1 & 0.177 & 1 & 1 & 1 & 1 & 0.184 \\
\hline
\end{tabular}

adverse events in the hospital. Core members of the senior management team are involved, and regular meetings are held weekly and monthly. High human resources investment highlights the hospital's emphasis on patient safety. This idea comes from the Hong Kong hospital management mode, where a special team under the quality and safety department focuses on incident management. Normally, there is no special team for incident management in hospitals in Mainland China, and the function is only a small part of a routine of medical administration department. In this aspect, HKUSZH seems to take initiative in patient safety in Mainland China. Because most HKUSZH staff members are from Mainland China, their perceptions of such new management strategies might be stronger, which might explain HKUSZH's higher results in terms of management's overall commitment to and prioritization of patient safety.

Management's commitment is crucial here, as leadership is important in implementing cultural change in healthcare. ${ }^{3}$ However, Scott et al ${ }^{3}$ indicated that a planned cultural change via such a top-down approach, instilling fresh values, beliefs, and working relationships in staff from the management level, is a complicated, difficult, and uncertain process. Such processes take time to become effective. In fact, this paper argues that HKUSZH's top-down approach to patient safety culture change has not been chosen by the organization itself but rather stems from the broader sociocultural environment. We argue that this is the epitome of authoritarianism in the Chinese society. Using a Japanese questionnaire to study the safety climate of Chinese hospitals, Gu and Itoh's study ${ }^{23}$ found that Chinese culture values authoritarianism, which in turn affects the patient safety climate of Chinese hospitals. The questionnaire items refer to authoritarianism as a hierarchical and bureaucratic environment where senior members have an absolute right to make management decisions. ${ }^{23} \mathrm{In}$ this context, this authoritarian sociocultural environment becomes one of the barriers to implementing a bottom-up approach. Another barrier might be the lagging patient safety management of Mainland China in general. Compared with staff members in Hong Kong, healthcare workers in the Mainland have outdated patient safety management knowledge, which might prevent them from feeling confident in their patient safety commitment and thus limit the development of a bottom-up process. In this case, we consider a top-down approach helpful to starting a patient safety culture change 
Table 5 Positive responses to the two extra questions, items and dimensions (\%)

Items and dimensions

HKUSZH

HKUSZH
Mainland China
Survey (20II)18
USA

Survey

$(2016)^{6}$

Results of the two extra questions:

I. "Overall grade on patient safety for the unit"

2. "The number of events they reported over the past 12 months"

DI. Teamwork within Units

al. People support one another in this facility

a3. When a lot of work needs to be done quickly, we work together as a team to get the work done

a4. In this facility, people treat each other with respect

al I. When one area in this unit gets really busy, others help out

D2. Supervisor/Manager Expectations and Actions Promoting Patient Safety

bl. My supervisor/manager gives praise when he/she sees a job done according to established patient safety procedures

b2. My supervisor/manager seriously considers staff suggestions for improving patient safety

b3r. Whenever pressure builds up, my supervisor/manager wants us to work faster, even if it means taking shortcuts

b4r. My supervisor/manager overlooks patient safety problems that happen over

and over

D3. Organizational Learning - Continuous Improvement

a6. We are actively doing things to improve patient safety

a9. Mistakes have led to positive changes here

al3. After we make changes to improve patient safety, we evaluate their

effectiveness

\section{D4. Management Support for Patient Safety}

fl. Hospital management provides a work climate that promotes patient safety

f8. The actions of hospital management show that patient safety is a top priority

f9r. Hospital management seems interested in patient safety only after an adverse event

D5. Feedback and Communication about Errors

$\mathrm{cl}$. We are given feedback about changes put into place based on event reports

c3. We are informed about errors that happen in this unit

c5. In this unit, we discuss ways to prevent errors from happening again

D6. Frequency of Events Reported

$\mathrm{dl}$. When a mistake is made but is caught and corrected before affecting the patient, how often is this reported?

d2. When a mistake is made but has no potential to harm the patient, how often is this reported?

d3. When a mistake is made that could harm the patient but does not, how often is this reported?

\section{D7. Overall Perceptions of Patient Safety}

a IOr. It is just by chance that more serious mistakes do not happen around here

al5. Patient safety is never sacrificed to get more work done

al7r. We have patient safety problems in this unit

a 18. Our procedures and systems are good at preventing errors

D8. Communication Openness

c2. Staff will freely speak up if they see something that may negatively affect patient care

c4. Staff feel free to question the decisions or actions of those with more authority

c6r. Staff are afraid to ask questions when something does not seem right

D9. Teamwork across Units

f2r. Hospital units do not coordinate well with each other

f4. There is good cooperation among hospital units that need to work together

f6r. It is often unpleasant to work with staff from other hospital units

fl0. Hospital units work well together to provide the best care for patients
84.90

45.70

87.4

90.20

85.25

90.52

83.44

80.8

88.74

89.47

58.00

86.80

78.0

92.18

55.12

86.75

75.5

82.62

83.88

59.87

71.8

58.05

69.80

87.46

64.0

46.69

72.85

72.33

$\mathbf{6 0 . 8}$

46.84

82.24

49.34

64.80

64.2

74.83

53.72

64.12

$\mathbf{5 0 . 0}$

34.22

56.38

51.66

57.81
73.00

1

84.0

87.00

87.00

80.00

81.00

63.0

1

76.00

45.00

82.0

87.00

87.00

81.00

71.00

78.0

78.00

76.00

80.00

36.00

77.00

78.00

79.00

88.0

73.0

87.00

1

89.00

84.00

64.00

70.00

69.0

72.0

81.00

76.00

61.00

70.00
65.00

68.0

60.00

69.00

75.00

67.0

62.00

63.00

75.00

66.0

55.0

61.00

64.00

65.00

73.00

64.0

77.00

65.0

51.00

49.00

65.00

61.0

49.00

62.00

63.00

71.00 
Table 5 (Continued)

\begin{tabular}{|c|c|c|c|}
\hline Items and dimensions & $\begin{array}{l}\text { HKUSZH } \\
\text { Survey }(2016)\end{array}$ & $\begin{array}{l}\text { Mainland China } \\
\text { Survey }(2011)^{18}\end{array}$ & $\begin{array}{l}\text { USA } \\
\text { Survey } \\
(2016)^{6}\end{array}$ \\
\hline DI0. Staffing & 32.9 & 45.0 & 54.0 \\
\hline a2. We have enough staff to handle the workload & 38.03 & 42.00 & 51.00 \\
\hline a5r. Staff members in this unit work longer hours than is best for patient care & 12.58 & 38.00 & 50.00 \\
\hline a7r. We use more agency/temporary staff than is best for patient care & 51.01 & 37.00 & 65.00 \\
\hline a 4 r. We work in this unit longer hours than is best for patient care & 30.13 & 61.00 & 49.00 \\
\hline DII. Handoffs and Transitions & 53.1 & 1 & 48.0 \\
\hline $\begin{array}{l}\text { f3r. Things "fall through the cracks" when transferring patients from one unit to } \\
\text { another }\end{array}$ & 40.13 & 1 & 43.00 \\
\hline f5r. Important patient care information is often lost during shift changes & 66.01 & 1 & 53.00 \\
\hline f7r. Problems often occur in the exchange of information across hospital units & 45.33 & 1 & 47.00 \\
\hline $\mathrm{fl} \mid \mathrm{r}$. Shift changes are problematic for patients in this hospital & 61.02 & 1 & 48.00 \\
\hline DI2. Non-punitive Response to Errors & 31.8 & 60.0 & 45.0 \\
\hline a8r. Staff members feel like their mistakes are held against them & 20.26 & 53.00 & 51.00 \\
\hline $\begin{array}{l}\text { a } 2 r \text {. When an event is reported, it feels like the person is being written up, not the } \\
\text { problem }\end{array}$ & 56.77 & 67.00 & 48.00 \\
\hline a 16r. Staff members worry that mistakes are kept in their personnel files & 18.42 & 60.00 & 37.00 \\
\hline Average (\%) & 62.5 & 64.5 & 64.8 \\
\hline
\end{tabular}

Note: "l" indicates that the item/dimension is not included in the research, so these data are missing. The "r" after the item number indicates a negatively worded item; the results of negatively worded items were recoded before analysis. Thus, all item results were calculated in the same way as the positively worded items. Bold figures in Table 5 are dimensional scores.

Abbreviations: D, dimension; HKUSZH, The University of Hong Kong - Shenzhen Hospital.

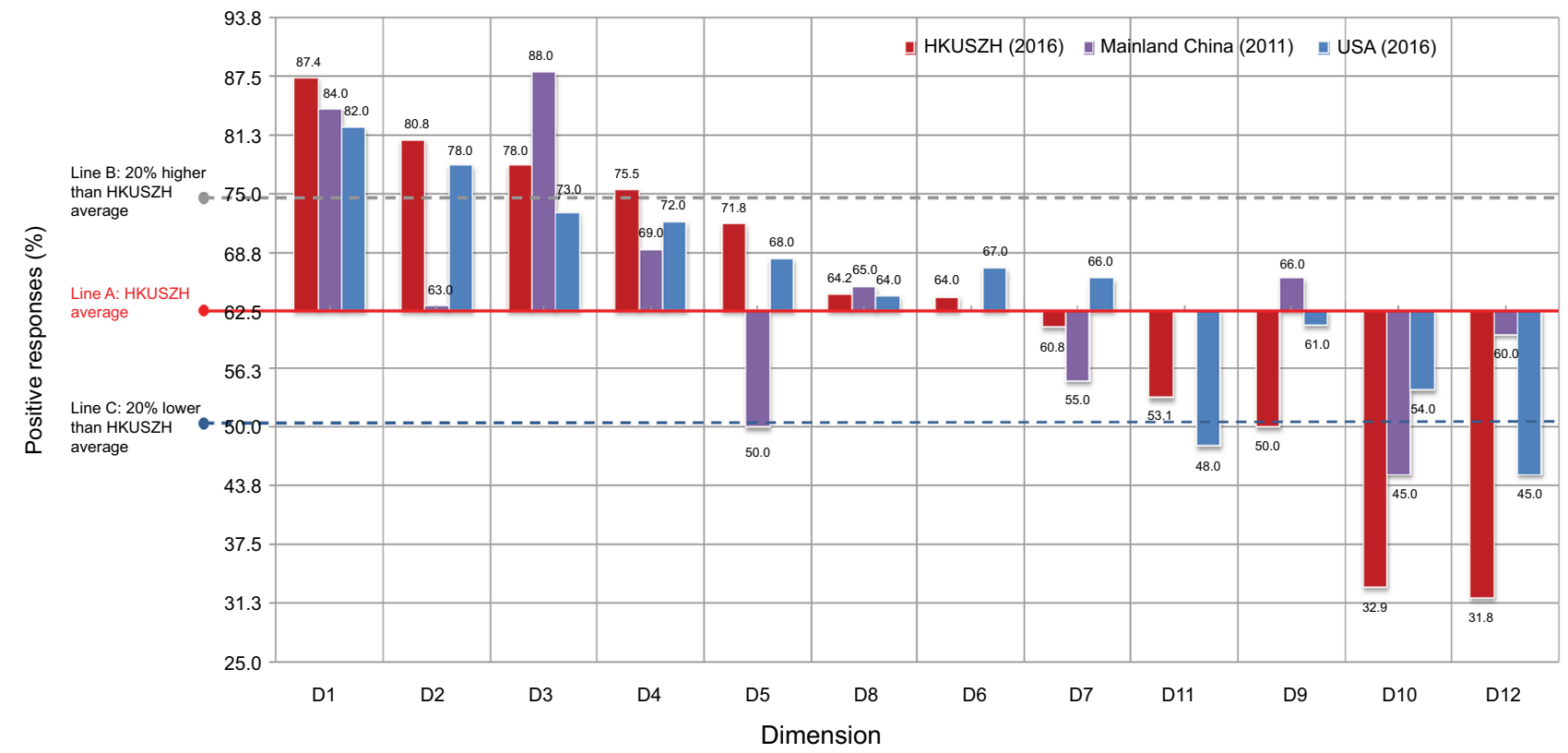

Figure I The distribution of dimensional positive response rate.

Abbreviations: D, dimension; HKUSZH, the University of Hong Kong - Shenzhen Hospital.

at HKUSZH. This would accelerate organizational learning of advanced management ideas from Hong Kong.

However, a Delphi study on clinical governance confirms that bottom-up approaches are more important for quality and safety in healthcare. ${ }^{24}$ This is also indicated in the MaPSaF, as a generative level of overall commitment to and prioritization of patient safety in an organization is that patient safety ideas and awareness should be embedded in all levels of staff and be seen in all actions. ${ }^{11}$ Therefore, our study suggests that ultimately, the management style needs to be converted from a top-down to a bottom-up approach to patient safety. Although HKUSZH has been a pioneer in Mainland China in terms of overall commitment to and prioritization of patient safety, one should consider whether its culture remains bureaucratic. As essential elements of an overall commitment to and prioritization of patient safety in the MaPSaF, ${ }^{11}$ future studies can explore staff incentives in audits related to safety issues and enthusiasm at all staff 
levels regarding participation in organizational safety issues and processes.

\section{An open and fair organization culture for patient safety: a call for an integrated incident management system}

An organization's perception and identification of the causes of incidents reveals whether its culture is open and fair. ${ }^{25}$ This section analyses incident perception and identification in light of our results for overall perceptions of patient safety, reporting rates, error communication, and non-punitive responses to error. An interesting finding is the respondents' contradictory feelings toward communication about errors and non-punitive response to errors. They seem keen on reporting and communicating errors but worry about the consequences of doing so. On the one hand, this might be a sign of people's enthusiasm for participating in patient safety management. But, on the other hand, it might also reveal that an open and fair hospital culture to support patient safety needs improvement.

Specifically, the HKUSZH results for the overall grading of patient safety, reporting frequency and error communication (D5) are higher than those found in the US and Mainland China surveys. These show that HKUSZH respondents reported a more positive hospital patient safety culture overall, and the HKUSZH has a good reporting culture wherein staff members are willing to talk about and actively report incidents. On the contrary, similar studies found that Chinese healthcare workers do not discuss incidents openly or report them actively. ${ }^{13,18,22}$ HKUSZH's efforts on incident management might contribute to the above phenomenon. For example, HKUSZH has an independent incident reporting system to identify patient safety incidents. Every staff member is responsible for reporting any patient safety issue they encounter, and the privacy of both the reporter and persons related to the incident are protected from bureaucratic pressure, thus reducing fear. Such an emphasis on voluntary and non-punitive reporting helps build an open and just incident reporting culture in the hospital. This healthy reporting culture might lead to the staff members' positive perceptions of patient safety. Most HKUSZH staff members were hired from traditional Chinese hospitals, where patient safety management is relatively underdeveloped. ${ }^{18,26}$ When they become employees of HKUSZH, they are exposed to an organizational culture wherein patient safety has a higher priority. Therefore, they might feel that the organization is doing more than their previous employers and might thus be more confident in the patient safety culture.
A reporting culture, summarized from the studies ${ }^{27,28}$ by Chiang et al, ${ }^{29}$ is a combination of the "shared values, attitudes, and behavioral patterns that determine the observable degree of efforts with which all healthcare workers direct their attentions and actions toward incident management and safety assurance at workplace." 29 The reporting culture and patient safety culture are closely connected. On the one hand, a reporting culture facilitates organization members' communication and action on patient safety. ${ }^{29-32}$ On the other hand, a healthy patient safety culture helps increase incident reporting. ${ }^{33}$ Thus, the high reporting rate in HKUSZH might be consistent with an acceptable patient safety culture in the hospital, which is, in turn, consistent with positive perceptions of overall patient safety culture. However, there are also contrasting views of incident reporting. For example, Billings $^{34}$ and Vincent ${ }^{35}$ indicated that the role of reporting has been overemphasized and that collecting incidents does not necessarily increase patient safety. Moreover, Vincent ${ }^{36,37}$ suggested that focusing on a small number of important incidents might be more valuable to patient safety culture. Improvement plans, actions, and evaluations deserve more attention. ${ }^{35}$ Overall, to improve patient safety, the focus should not be solely on incident reporting.

An unexpected finding in the HKUSZH survey is that non-punitive response to errors (D12) is a weakness. Staff members seem to worry that error will remain on their personal records and hold back their career development. As indicated before, HKUSZH's incident management contributes to an open and just management culture. It also initiates a changing culture around the blame for error. For example, instead of simply considering human factors and blaming staff, a systematic method, RCA, is adopted to identify system-level causes. These features improve error reporting and communication but fail to reduce the fear of punitive consequence for errors. Sociocultural factors might be one reason. As illustrated in the last section, Chinese society is authoritarian and hierarchical, and these characteristics limit the development of a patient safety culture in Chinese hospitals. ${ }^{22}$ It is difficult to relieve the worries of a Chinese staff about punitive consequence in such a deep-rooted authoritarianism culture, even in a relatively open hospital culture.

Apart from the sociocultural factors, our study suggests that a lack of an integrated incident management holds back the hospital's non-punitive culture. The first example concerns the system structure. The Chief of Service (COS) mechanism from Hong Kong hospital management was introduced to HKUSZH as part of its organizational structure. This means that decision-making authority in each 
department mostly belongs to the COS. Thus, although the IMT is in charge of overall incident management, the COS makes detailed decisions about the causes, actions for improvement, and staff members involved in the incident. However, if an incident is related to patient relations, such as complaints and medical disputes from patients, the Patient Relations Office will handle the case. The above illustrations show that the system structure seems split. Second, the authorities do not have a unified understanding of the important issues. Although HKUSZH emphasizes systemlevel causes, there seems to be insufficient clarification of, for example, human factors and system factors. Patient safety incidents usually involve more than one interest group or individual. Without unified concepts and definitions, there may be diverse understandings and misunderstandings of causes. For instance, Gu and Itoh's ${ }^{23}$ study on safety climate in Chinese hospital found that insufficient clarification and related education on human factors caused Chinese healthcare workers to have unrealistic understandings of human error. When understandings of error and causal factors are not unified at the hospital level, staff members are not clear about where and how their professional responsibilities fit into the non-punitive culture. ${ }^{38}$ They fear that what they hear might be different from how they are actually treated. Thus, ambiguity about human factors and system factors might lead to distrust of the open and just culture that HKUSZH aims to promote. This ambiguity also suggests the separation of the safety culture from quality and the organizational culture as a whole, and it does not contribute to a professional patient safety culture. ${ }^{38}$ In the MaPSaF, an organization with a high level of openness and trust will have "integrated systems [that] enable patient safety incidents, complaints and litigation cases to be analyzed together." 11 A lack of an integrated incident management system is a barrier to improving the non-punitive culture of HKUSZH.

In sum, our study suggests that HKUSZH has an appropriate understanding toward errors. It considers both human and system factors in incidents. However, it lacks an integrated incident management system. Its open and fair culture does not seem to be completely trusted by all staff members, who feel safe enough to communicate errors but still worry about the consequences. It is concluded that the current open and fair patient safety culture of HKUSZH is moving toward the proactive level but currently remains bureaucratic:

Bureaucratic: $[\ldots]$ recognition that systems contribute to incidents and not just individuals. The organization says that it has an open and fair culture but it is not perceived in that way by staff. A centralized anonymous reporting system is in place with [...] emphasis on form completion. Attempts are made to encourage staff $[\ldots]$ to report incidents $[\ldots .$.

Proactive: $[. .$.$] accepted that incidents are a combina-$ tion of individual and system faults. Reporting of patient safety incidents $[\ldots]$ is encouraged and $[\ldots]$ seen as learning opportunities. Accessible, "staff friendly" electronic reporting methods are used [...] Staff feels safe reporting patient safety incidents. Staff, patients and relatives are involved and supported from the moment of reporting through a being open process. The organization has an open, fair and collaborative culture. ${ }^{11}$

\section{Teamwork for patient safety: insufficient and inefficient team building}

Teamwork is part of patient safety culture in the MaPSaF. ${ }^{11}$ HKUSZH's survey results for teamwork within units (D1) is the highest of all dimensions and higher than in the US and Mainland China surveys. On the contrary, HKUSZH's result for teamwork across units (D9) is relatively lower. In other words, the staff members in a unit treat each other with respect and support each other during busy times, but they do not seem to coordinate well with their colleagues in other units.

In a survey of Mainland China, Nie et a ${ }^{18}$ report similar findings on teamwork within units. They argue that the prioritization of harmony in Chinese culture is related to strong teamwork within units in the Chinese sample. However, our study suggests that Chinese culture might not be the main factor, since the above results are also found in studies conducted in other culture settings, such as the USA, ${ }^{6}$ the Netherlands ${ }_{2}{ }^{12}$ and Taiwan. ${ }^{39}$ In Street and Coleman's hospital ethnography, ${ }^{40}$ they argue that boundaries are important hospital characteristics. They indicate that biomedical and bureaucratic knowledge divide the hospital space into different units in order to group staff members, related technologies and spaces into the same specialty to facilitate medical practice. This natural characteristic of medical practice and hospitals might contribute to stronger teamwork within hospital units than across units.

HKUSZH's findings on teamwork also suggest insufficient team building. The following description is included in the MaPSaF on bureaucratic teamwork and patient safety:

Teams are put together to respond to policies [...] no way of measuring how effective they are $[. .$.$] Teamwork is seen$ by lower grades [...] as paying lip service to the idea of empowerment $[. .$.$] little sharing of ideas or information$ about safety issues across teams. ${ }^{11}$ 
Some situations might be similar at HKUSZH. For example, committees or cross-sectional teams seem to be formed because of government policies or hospital accreditation criteria. The members of such teams might seldom meet, meeting only to fulfill policy requirements, regardless of effectiveness. Thus, our study considers the hospital's current teamwork on patient safety mostly bureaucratic. More efficient team building is needed to motivate all levels of the organization to take part in safety issues. A desirable culture of teamwork for patient safety is mentioned in the MaPSaF:

Generative: [...] Team membership is flexible, with different people making contributions when appropriate. Teams are about shared understanding and vision about safety issues rather than geographical proximity [...] Everyone is equally valued and feels free to contribute. "Everybody is part of the risk management team," this includes all levels of the organisation from Board members through to those who have day-to-day contact with patients. ${ }^{11}$

\section{Culture change in hospital personnel management for patient safety: a matter of time or culture resistance?}

Healthcare personnel directly affect healthcare service delivery and its quality. ${ }^{41}$ Personnel management is one dimension of the MaPSaF that affects the patient safety culture. ${ }^{11}$ The survey suggests that staffing (D10) is a weakness in HKUSZH's patient safety culture. For example, the results suggest that participants felt that their working hours are too long to provide good patient care. Their heavy workload negatively affects service quality. Such a finding is consistent with several Chinese studies. ${ }^{18,20,22,39}$ Moreover, in Zhu et al's qualitative study, ${ }^{13}$ Chinese healthcare workers expressed concerns about staff shortages and considered this the biggest challenge for patient safety, especially the shortage of nurses. Hence, one could infer that healthcare staffing is a common problem in the country. The WHO reported that China's healthcare workforce density is only in the third quintile among all 186 countries for which it has data. ${ }^{42}$ Specifically, the ranking of Chinese physician density is 85 of $195,{ }^{43}$ while that of Chinese nursing and midwifery is 110 of $190 .{ }^{44}$ Thus, although China is not experiencing a healthcare workforce crisis, it needs more healthcare workers to share the workload generated by its large population. Moreover, the HKUSZH results for staffing support the findings of You et $\mathrm{a}^{45}$ on health workers in Shenzhen, China, where HKUSZH is located. Their study indicated that the health workforce density in Shenzhen city is the lowest of
15 subprovincial cities. ${ }^{45}$ Thus, the HKUSZH findings might also reflect the city's health care workforce problem.

As an experimental public hospital, HKUSZH is initiating cultural change in healthcare personnel management in Mainland China. For example, the privatization of Chinese public hospitals and healthcare reform induces the hospitals to make profits by taking in more patients regardless of their existing workload. Chinese healthcare workers feel that they are too tired to provide good service, which harms patient safety. Aiming to change this situation, HKUSZH disconnects staff income from organizational income by introducing a fixed salary mechanism. The salary level is higher than that of traditional Chinese hospitals. This increases the value of Chinese healthcare workers. Additionally, the clinical staff members at HKUSZH need to meet only a daily target by seeing a reasonable number of patients. Instead of pursuing volume, they are required to spend more time on each patient, for example, at least 15 minutes. In sum, HKUSZH aims to change the diagnostic culture of Chinese public hospitals, where only the number of patients served is highlighted. Nevertheless, it is a pity to see that HKUSZH's patient safety culture survey results do not seem to support its desire for this cultural change. Negative feelings among staff members about the workload still exist. The authors of this paper wonder whether culture change requires more time or whether there is cultural resistance to the application of hospital personnel management strategies from Hong Kong. This issue needs to be further explored.

According to the MaPSaF, an organization with a generative patient safety culture in personnel management is described as follows:

[...] everyone has confidence in the personnel management procedures. Personnel management is not a separate entity but an integral part of the organization. Reflection and review about safety issues occur continuously and automatically $[\ldots]$ Following a patient safety incident, a systems analysis is used $[\ldots]$ to make decisions about the relative contribution of systems factors and the individual healthcare professional $[\ldots]$ there is a consistent and fair approach to dealing with staff issues following incidents. ${ }^{11}$

Because the necessary information is lacking here, it is difficult to tell what HKUSZH's level of patient safety culture is from the angle of staffing. Further studies are suggested in aspects such as the integration of personnel management procedures into the organization system for patient safety, and a consistent and just way to investigate incidents and manage human factors after an investigation. 


\section{Limitations}

This paper has limitations that serve to highlight areas for future study. The first is a lack of exploration of differences across groups. It would be meaningful for future studies to conduct qualitative studies regarding what different groups think about issues such as the acceptance of the new culture, strengths, and areas for improvement. The second is a lack of exploration of effective approaches to changing the patient safety and organizational culture mentioned in the literature. Future studies could focus on determining what the literature says about approaches that work and those that do not work.

\section{Conclusions}

This study explored the current patient safety culture of an experimental Chinese hospital. Its differences and similarities with other Chinese hospitals were explored. Population characteristics affect perceptions of patient safety culture at HKUSZH. Deeper qualitative research needs to be conducted, especially on why doctors feel less positive than the other professional groups. HKUSZH's important efforts and achievements in patient safety culture are recognized. However, HKUSZH's patient safety culture needs further development, as it is mostly bureaucratic. The main management challenges lie in the top-down approach to patient safety culture change, the open and fair environment, teamwork, and personnel management. For better patient safety, topdown culture change needs to be converted into bottom-up change to ensure that management ideas are disseminated to and embedded in all staff levels. Additionally, an integrated incident management system is needed and additional effort is suggested to improve team building and staffing.

\section{Data sharing statement}

The dataset used and/or analyzed during the current study is available from the corresponding author upon reasonable request.

\section{Acknowledgments}

We would like to thank Endre László Halasi for his encouragement and practical suggestions for this paper. We are also grateful to Ai Ming Tan and to all other members of the Clinical Service Departments for their support during this research, as well as to the entire staff of the University of Hong Kong - Shenzhen Hospital who participated in our survey. Last, but not least, we would like to acknowledge a financial contribution from the Shenzhen Science and Innovation Committee under project number JCYJ20150331142757382.

\section{Disclosure}

The authors report no conflicts of interest in this work.

\section{References}

1. International Nuclear Safety Advisory Group. Basic Safety Principles for Nuclear Power Plants. International Atomic Energy Agency, Vienna. Safety Series; 1988; No. 75-INSAG-3.

2. Health and Safety Commission. Organising for Safety: Third Report of the ACSNI (Advisory Committee on the Safety of Nuclear Installations) Study Group on Human Factors. Sudbury, England: HSE Books. 1993.

3. Scott T, Mannion R, Davies HT, Marshall MN. Implementing culture change in health care: theory and practice. Int $J$ Qual Health Care. 2003;15(2):111-118.

4. Westat.Agency for Healthcare Research and Quality (AHRQ). Hospital Survey on Patient Safety Culture. Background and Information for Translators. Report for the Agency for Healthcare Research and Quality; 2009. Contract number HHSA 290200710024C. September. Available from: https:/www.ahrq.gov/sites/default/files/wysiwyg/professionals/ quality-patient-safety/patientsafetyculture/hospital/resources/infotranshsops.pdf. Accessed February 28, 2018.

5. Sammer CE, Kristine L, Singh KP, Mains DA, Lackan N A. What is patient safety culture? a review of the literature. J Nurs Scholarsh 2010;42(2):156-165.

6. Famolaro T, Yount N, Burns W, et al. Hospital Survey on Patient Safety Culture 2016 User Comparative Database Report. (Prepared by Westat, Rockville, MD, under Contract No. HHSA 290201300003C). Rockville, MD: Agency for Healthcare Research and Quality. AHRQ Publication No. 16-0021-EF; 2016.

7. Westrum R. Cultures with requisite imagination. In: Wise J, Stager P, Hopkin J. editors. Verification and Validation in Complex Man-Machine Systems. NATO ASI Series (Series F: computer and systems sciences). Springer, Berlin, Heidelberg. 1993.

8. Hale AR. Culture's confusions. Safety Science.2000;34:1-14

9. Parker D, Lawrie M, Hudson P.A framework for understanding the development of organizational safety culture. Saf Science. 2006;44(6):551-562.

10. Reason J. Managing the Risks of Organizational Accidents. 1st ed. Aldershot: Ashgate; 1997

11. The University of Manchester. Manchester Patient Safety Framework (MaPSaF); 2006.Available from: http://www.nrls.npsa.nhs.uk/ resources/?entryid45=59796. Accessed October 7, 2016.

12. Wagner C, Smits M, Sorra J, Huang CC. Assessing patient safety culture in hospitals across countries. Int J Qual Health Care. 2013;25(3):213-221.

13. Zhu J, Li L, LiY, et al. What constitutes patient safety culture in Chinese hospitals? Int J Qual Health Care. 2012;24(3):250-257.

14. Nie Y, Li Y, Ning J, Hou Y, Huang Y, Zhang M. Patient safety research in china: a literature review. J Evid Based Med. 2011;4(2):66-72.

15. State Council of China. [On further encouraging and guiding social capital to engage in healthcare institution establishment; 2010:58 China]. [In Chinese] Available from: http://www.gov.cn/zwgk/201012/03/content_1759091.htm. Accessed August 03, 2016.

16. Gauld R, Gould D. 'Establishment of the hospital authority' in The Hong Kong Health Sector: Development and Change. Hong Kong: Chinese University Press; 2002:71.

17. World Health Organization (WHO). Global priorities for patient safety research: Better knowledge for safer care; 2009. Available from: http://www.who.int/patientsafety/research/priorities/global_priorities_patient_safety_research.pdf. Accessed October 1, 2016.

18. Nie Y, Mao X, Cui H, He S, Li J, Zhang M. Hospital survey on patient safety culture in China. BMC Health Serv Res. 2013;13(1):228.

19. Mao X, Nie Y, Cui H, Jia P, Zhang M. Literature review regarding patient safety culture. J EvidBased Med. 2013;6(1):43-49.

20. Jia $\mathrm{P}$, Zhang L, Mao X, Zhang M. Fostering patient safety culture in hospital to improve health service: hospital survey on patient safety culture. Value Health. 2014;17(7):A796-A797. 
21. Sorra J, et al. AHRQ Hospital Survey on Patient Safety Culture: User's Guide. (Prepared by Westat, under Contract No. HHSA290201300003C). AHRQ Publication No. 15-0049-EF (Replaces 04-0041). Rockville, MD: Agency for Healthcare Research and Quality. January. 2016. http:// www.ahrq.gov/professionals/quality-patient-safety/patientsafetyculture/ hospital/index.html. Accessed 15 Oct. 2016.

22. Zhu J, Li L, Zhou Z, Lou Q, Wu AW. Variations in patient safety climate in Chinese hospitals. J Patient Saf. Epub 2016 Sep 9.

23. Gu X, Itoh K. A pilot study on safety climate in Chinese hospital. J Patient Saf. 2011;7(4):204-212.

24. Veenstra GL, Ahaus K, Welker GA, Heineman E, van der Laan MJ, Muntinghe FL. Rethinking clinical governance: healthcare professionals' views: a Delphi study. BMJ Open. 2017;7:1-7.

25. Shaw R. Patient safety: the need for an open and fair culture. Clin Med (Lond). 2004;4(2):128-131.

26. Cao RG. [Medical quality and patient safety in China]. Chinese Hospitals. 2007;11(11):1-4. Chinese.

27. Cooper MD. Towards a model of safety culture. Saf Sci. 2000;36: 111-136.

28. Smetzer J, Navarra MB. Measuring change: a key component of building a culture of safety. Nurs Econ. 2007;25(1):49-51.

29. Chiang HY, Lin SY, Hsiao YC, Chang Y. Culture influence and predictors for behavioral involvement in patient safety among hospital nurses in Taiwan. J Nurs Care Qual. 2012;27(4):359-367.

30. Institute of Medicine. To Err is Human: Building a Safer Health System. Washington, DC: National Academies Press; 2000.

31. Waring JJ. Beyond blame: cultural barriers to medical incident reporting. Soc Sci Med. 2005;60(9):1927-1935.

32. Kingston MJ, Evans SM, Smith BJ, Berry JG. Attitudes of doctors and nurses towards incident reporting: a qualitative analysis. Med J Aust. 2004;181(1):36-39.

33. Birk K, Padjen L, Markič M. Adverse event reporting in Slovenia: The influence of safety culture, supervisors and communication. Vojnosanit Pregl. 2016;73(8):714-722.

34. Billings $\mathrm{C}$. Incident reporting systems in medicine and experience with the aviation reporting system. In Cook RI, Woods DD, Miller CA, editors. A Tale of Two Stories: Contrasting Views of Patient Safety. North Adams, MA: US National Patient Safety Foundation; 1998:52-61.
35. Vincent C. Incident reporting and patient safety. BMJ. 2007; 334(7584):51.

36. Vincent C. Patient safety. Edinburgh: Elsevier Churchill Livingstone; 2006.

37. Vincent CA. Analysis of clinical incidents: a window on the system not a search for root causes. Qual Saf Health Care. 2004;13(4): 242-243.

38. Hellings J, Schrooten W, Klazinga N, Vleugels. A challenging patient safety culture: survey results. Int J Health Care Qual Assur. 2007;20(7): 620-632.

39. Chen IC, Li HH. Measuring patient safety culture in Taiwan using the Hospital Survey on Patient Safety Culture (HSOPSC). BMC Health Serv Res. 2010;10:152.

40. Street A, Coleman S. Introduction: Real and Imaginary Spaces' Hospital heterotopias: ethnographies of biomedical and non-biomedical spaces. Space Culture. 2012;15(1):1-18.

41. Kabene SM, Orchard C, Howard JM, Soriano MA, Leduc R. The importance of human resources management in health care: a global context. Human Resour Health. 2006;4(1):20.

42. Campbell J, Dussault G, Buchan J, et al. A universal truth: no health without a workforce. Forum Report, Third Global Forum on Human Resources for Health, Recife, Brazil. Geneva; 2013. Available from: http://www.who.int/workforcealliance/knowledge/resources/hrhreport2013/en/. October 15, 2016.

43. World Health Organization (WHO). Global Health Observatory visualizations-Health workforce: Physicians: density per 1000 population; 2015a. Available from: http://gamapserver.who.int/gho/interactive_charts/health_workforce/PhysiciansDensity_Total/atlas.html. Accessed October 1, 2016.

44. World Health Organization(WHO). Global Health Observatory visualizations-Health workforce: Nursing and midwifery personnel: density per 1000 population; $2015 \mathrm{~b}$. Available from: http://gamapserver.who.int/ gho/interactive_charts/health_workforce/NursingMidwiferyDensity/ atlas.html. Accessed October 1, 2016.

45. You HJ, Lu K, Yu LY, Chen SX. [Status quo analysis of health human resource in Shenzhen]. Chinese Rural Health Service Administration. 2016;36(3):293-296. Chinese.
Risk Management and Healthcare Policy

\section{Publish your work in this journal}

Risk Management and Healthcare Policy is an international, peer-reviewed, open access journal focusing on all aspects of public health, policy, and preventative measures to promote good health and improve morbidity and mortality in the population. The journal welcomes submitted papers covering original research, basic science, clinical and epidemiological

\section{Dovepress}

studies, reviews and evaluations, guidelines, expert opinion and commentary, case reports and extended reports. The manuscript management system is completely online and includes a very quick and fair peerreview system, which is all easy to use. Visit http://www.dovepress.com/ testimonials.php to read real quotes from published authors. 